University of Wollongong

Research Online

Australian Institute for Innovative Materials -

Papers

Australian Institute for Innovative Materials

$1-1-2017$

Investigations into the electrochemical etching process of p-type silicon

using ethanol-surfactant solutions

Sivakumar Balakrishnan

CSIRO, University of Wollongong

Yurii K. Gun'ko

Gerhard F. Swiegers

University of Wollongong, swiegers@uow.edu.au

Tatiana S. Perova

Follow this and additional works at: https://ro.uow.edu.au/aiimpapers

Part of the Engineering Commons, and the Physical Sciences and Mathematics Commons

Research Online is the open access institutional repository for the University of Wollongong. For further information contact the UOW Library: research-pubs@uow.edu.au 


\title{
Investigations into the electrochemical etching process of p-type silicon using ethanol-surfactant solutions
}

\author{
Abstract \\ In this work, the electrochemical etching of p-type silicon was performed in aqueous ethanol-surfactant \\ solutions and the dependence of morphology and luminescent properties of porous silicon with respect \\ to the etching parameters and silicon resistivities have been studied. The obtained porous silicon \\ structures have been studied using various characterisation techniques such as SEM (Scanning Electron \\ Microscopy) and Photoluminescence (PL) spectroscopy.

\section{Keywords} \\ into, silicon, electrochemical, ethanol-surfactant, solutions, etching, process, investigations, p-type \\ Disciplines \\ Engineering | Physical Sciences and Mathematics \\ Publication Details \\ Balakrishnan, S., Gun'ko, Y. K., Swiegers, G. F. \& Perova, T. S. (2017). Investigations into the \\ electrochemical etching process of p-type silicon using ethanol-surfactant solutions. AIP Conference \\ Proceedings, 1884 (1), 030007-1-030007-4.
}




\title{
Investigations Into the Electrochemical Etching Process of P-Type Silicon Using Ethanol-Surfactant Solutions
}

\author{
Sivakumar Balakrishnan, ${ }^{1,2, b)}$ Yurii K Gun'ko, ${ }^{1}$ Gerhard F Swiegers ${ }^{2}$ and \\ Tatiana S Perova ${ }^{3,4, \text { a) }}$ \\ ${ }^{1}$ School of Chemistry, Trinity College Dublin, The University of Dublin, Dublin 2, Ireland \\ ${ }^{2}$ Intelligent Polymer Research Institute, University of Wollongong, NSW 2522, Australia \\ ${ }^{3}$ School of Engineering, Trinity College Dublin, The University of Dublin, Dublin 2, Ireland \\ ${ }^{4}$ ITMO University, St Petersburg, 197101 Russia

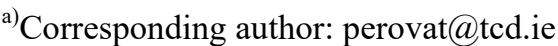 \\ b)balasivam@gmail.com
}

\begin{abstract}
In this work, the electrochemical etching of p-type silicon was performed in aqueous ethanol-surfactant solutions and the dependence of morphology and luminescent properties of porous silicon with respect to the etching parameters and silicon resistivities have been studied. The obtained porous silicon structures have been studied using various characterisation techniques such as SEM (Scanning Electron Microscopy) and Photoluminescence (PL) spectroscopy.
\end{abstract}

\section{INTRODUCTION}

The etching of Si leads to micro-machined products which in turn allows the integration of micro-mechanisms in single devices with potential applications in micro-robotic systems [1]. Electrochemical etching of Si in hydrofluoric (HF) acid electrolyte is a well-known technique for the fabrication of porous silicon [2]. The structure and morphology of a porous $\mathrm{Si}$ can be changed during an etching process, and different type of electrolytes have been used for the etching of Si, resulting in the interest in the material over the past few decades. Majority of porous Si research were focused on the preparation of $n$-type porous silicon and comparatively less reports are known on the fabrication of $p$-type silicon [3]. The first report of the fabrication of macropores on $p$-type $\mathrm{Si}$ was published using acetonitrile as the solvent [4] and it has been reported that in aqueous or alcoholic fluoride solutions, the electrochemical formation of macropores on $p$-type Si occurs only in low-doped substrate [5]. One of the main advantages of preparing $p$-type porous silicon is that it doesn't require any backside or front-side illumination [6], in contrast to the $n$-type Si.

If macropores in $p$-type $\mathrm{Si}$ using organic electrolyte came as a surprise, so did the macropores in $p$-types silicon using aqueous electrolytes [7]. It has been noted previously that the additions of ethanol $\left(\mathrm{C}_{2} \mathrm{H}_{5} \mathrm{OH}, \mathrm{EtOH}\right)$ and/or Isopropanol $\left(\mathrm{C}_{3} \mathrm{H}_{7} \mathrm{OH}\right)$, or similar alcoholic solutions can reduce surface tension, adjusts the viscosity and facilitates the easy removal of hydrogen from the porous layer [8]. The formation of micropores in porous silicon has been studied well, and the transitions from micropores to mesopores depend on parameters such as doping level, current density and HF concentration. Following, the discovery of peculiar optical properties of microporous Si in 1990 [9,10], the application was focused onto various Si based optoelectronic, electronic, electromechanical, optical and biological devices, which required a patterning of porous silicon in defined geometrical layouts [11]. Even though, alcohol based etching process is reported for porous Si formation, there is still little attention has been paid onto the effect of alcohol on this process [8]. In this paper, we investigate some of the properties that depend on porous Si fabrication and report on how the variation in pore structures can be affected when the processing conditions/parameters are changed. The SEM and PL spectroscopy served as the main tools for characterisation. 


\section{EXPERIMENTAL}

Czochralski-grown single crystal $p$-type silicon wafers of (100) orientation were used for the present studies. An aluminium thin film was deposited on the backside of the wafer prior to etching. All the chemicals were purchased from Aldrich unless otherwise stated. Electrolytes were prepared by mixing of HF (Lennox Laboratories Supplies), ethanol (99.5\%) and de-ionized Millipore water at different volume ratios. The electrolyte composition for a typical anodization was set at a ratio of 1: 1: $1 \mathrm{HF}: \mathrm{C}_{2} \mathrm{H}_{5} \mathrm{OH}: \mathrm{H}_{2} \mathrm{O}+10^{-3}$ M CTAC (CTAC - Cetyltrimethylammonium chloride), named further as a SOL-1. Si (100) wafers of resistivity $\rho=17 \Omega \cdot \mathrm{cm}$ were etched with a galvanostatic anodic etching, using a current densities, $J$, of $35 \mathrm{~mA} / \mathrm{cm}^{2}$ for 1 hour, $32 \mathrm{~mA} / \mathrm{cm}^{2}$ for 3.5 hours and $40.6 \mathrm{~mA} / \mathrm{cm}^{2}$ for 5 hours in SOL-1. Further to determine the influence of etching time, $t$, on porosity and pore depth, $d$, silicon wafers of low resistivity $\rho=0.02 \Omega \cdot \mathrm{cm}$ were used with different etching times of 30,120 and 180 minutes by keeping the constant average current density, $J_{A V}$. The influence of Si resistivity on pore depth and morphology of the samples was determined using Si wafers with resistivities $0.02,5.69,14.85$ and $17 \Omega \cdot \mathrm{cm}$ with $J_{A V}=10 \mathrm{~mA} / \mathrm{cm}^{2}$ and $t=60$ min.

Room temperature photoluminescence (PL) spectra were recorded using a Renishaw 1000 micro-Raman system with the excitation wavelength of $514.5 \mathrm{~nm}$ from an $\mathrm{Ar}^{+}$ion laser. A typical laser power was kept at $\sim 3 \mathrm{~W} / \mathrm{cm}^{2}$ in order to avoid excessive sample heating. SEM images of the samples were obtained using an FESEM (Hitachi S-4300 scanning electron microscope), which was operated at $5.0 \mathrm{kV}$ or $20 \mathrm{kV}$.

\section{RESULTS AND DISCUSSION}

Table 1 shows the parameters and the obtained porosity for the porous silicon samples. Figure 1 shows the dependencies of morphology of the porous $\mathrm{Si}$ samples on the current densities and etching time. It can be seen that $\mathrm{Si}$ samples etched with $J=35 \mathrm{~mA} / \mathrm{cm}^{2}$ for one hour (Figs. 1a,b) showed branched, slightly curvy porous structures with $\mathrm{Si}$ nanowires protruding from the edges of the porous Si walls. When the current density was slightly decreased and etching time was increased to 3.5 hours, the morphology of samples has completely changed. Figures 1c,d show SEM images of the sample etched with an initial current density $J=32 \mathrm{~mA} / \mathrm{cm}^{2}$ for 3.5 hours. Here the formation of uniform smooth pores with high aspect ratio can be observed. The formation of macropores with deep and thick pore walls suggests the role of CTAC as a pore wall modifier [12]. This is further evidenced from increasing the current density to $40 \mathrm{~mA} / \mathrm{cm}^{2}$ and etching time to 5 hrs (Figs. 1e,f) when the pores showed thin and broken pore walls. Thus an optimum current density and etching time is needed to obtain a uniform, smooth pore walled porous Si samples.
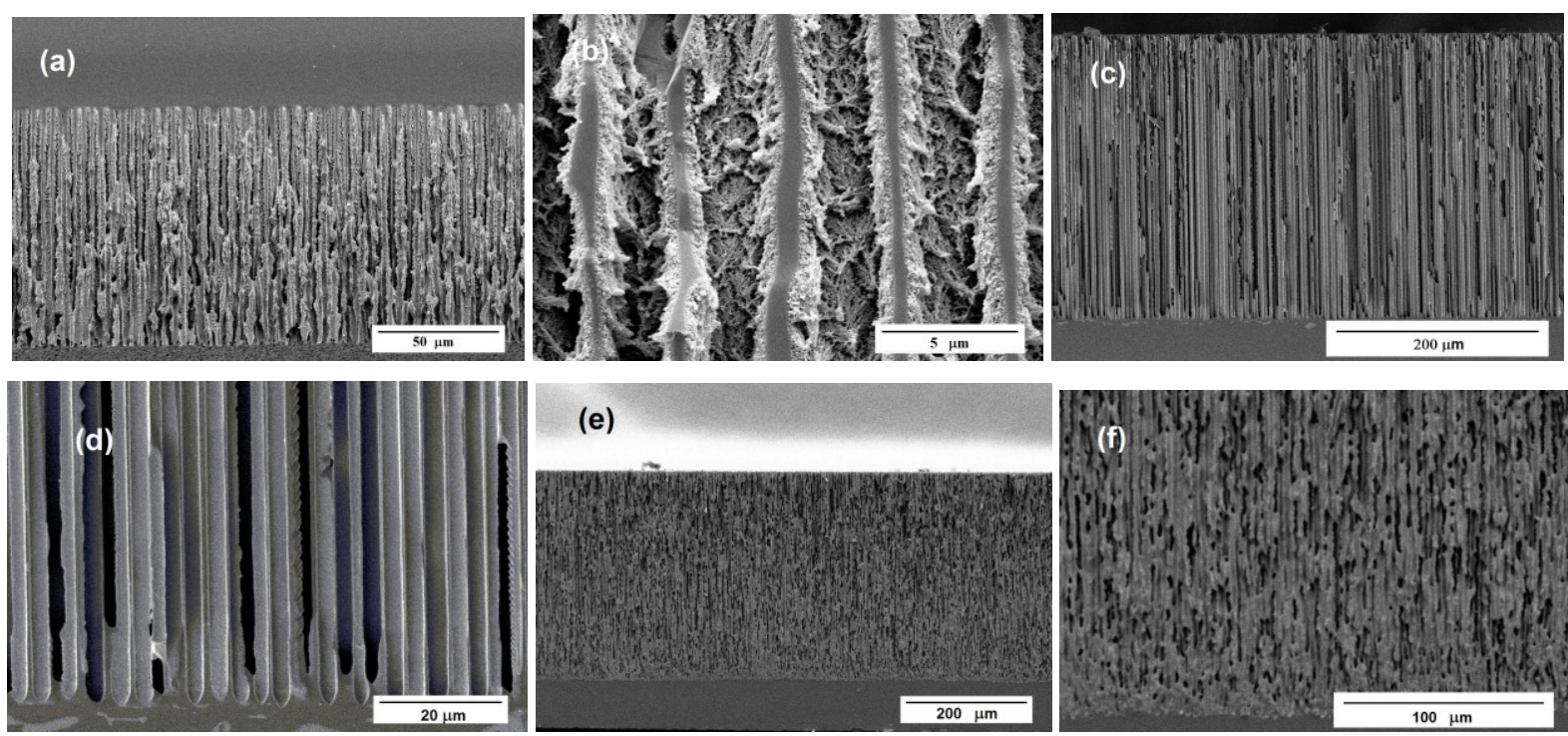

FIGURE 1. SEM images of porous Si samples at different $J$ and $t$ using SOL-1: (a) \& (b) $J=35 \mathrm{~mA} / \mathrm{cm}^{2}$; (c) \& (d) $J=32 \mathrm{~mA} / \mathrm{cm}^{2}$; (e) $\&$ (f) $J=40 \mathrm{~mA} / \mathrm{cm}^{2}$. (b, $\mathrm{d}$ and $\mathrm{f}$ are the corresponding enlargement of figures a, c and e). 
The role of CTAC is evident from the formation of uniform macropores and it has been reported that during the anodization process, amphiphilic surfactants can adsorb onto the surface of the electrode, with their non-polar tails attached on the hydrophobic silicon surface [12]. The density of adsorbed surfactant on the sidewall of macropores could be higher than that at the tip region due to geometric constraint. This may modify the wetting properties of silicon surface as well as the electric field at the interface, which may, in turn, protect the sidewalls against dissolution. With the higher current density, the rate of modification process by the surfactant is exceeded by increasing current and may have resulted in the thin broken wall as observed in Figs. 1e,f.

TABLE 1. Parameters for electrochemical etching of Si samples in SOL-1.

\begin{tabular}{|l|ccc|}
\hline Samples & (a) & (b) & (c) \\
\hline Time $(\mathrm{min})$ & 30 & 120 & 180 \\
$\rho(\Omega \mathrm{cm})$ & 0.02 & 0.02 & 0.02 \\
$J_{A V}\left(\mathrm{~mA} \cdot \mathrm{cm}^{-2}\right)$ & 34.47 & 34.53 & 34.46 \\
$\Delta m(\mathrm{~g})$ & 0.0035 & 0.0191 & 0.0296 \\
$d(\mu \mathrm{m})$ & 50 & 220 & 295 \\
Porosity $(\%)$ & 46.23 & 57.32 & 66.49 \\
\hline
\end{tabular}

The linear dependence of the pore depth versus the etching time, shown in Fig. 2a, is similar to what has been observed by other authors in porous $\mathrm{Si}$ etched with aqueous electrolytes [12]. Fig. 2a also shows the gradual increase of porosity with respect to the etching time and this may be due to the fact that the porosity depends not only on the pore depth but also on the pore diameter as well as on the density of pores. The variation of porosity was also studied with respect to the current density (Fig.2b) and it can be seen that the porosity increases linearly up to $60 \mathrm{~mA} / \mathrm{cm}^{2}$ and then it attained saturation in porosity at higher current densities. The branching of pores at high current density may be one reason for more or less stable porosity at higher current density. So, when the current density is increased, it will lead to the formation of more branched pores or electro-polishing may have occurred at higher current densities. The dependence of PL on the current density was investigated and the results are shown in Fig. 3. As can be seen from Fig. 3, the intensity of the PL emission increases with the current density for a fixed electrolyte concentration. The existence of PL at higher current densities could be due to the formation of microporous region within the macroporous Si layers.
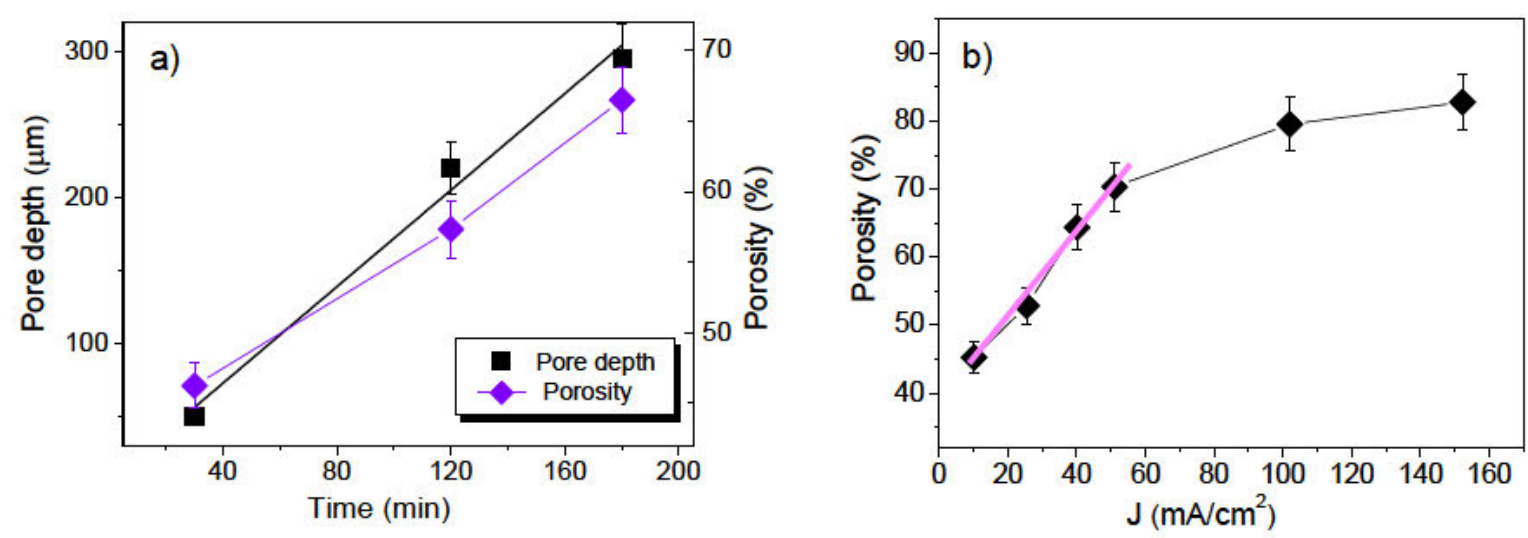

FIGURE 2. a) The linear dependence of pore depth and porosity vs etching time. b) The dependence of porosity vs current density. 


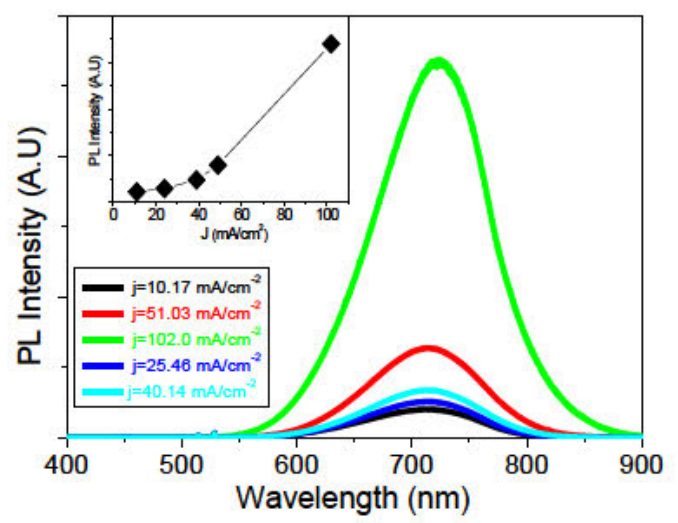

FIGURE 3. Photoluminescence spectra of porous $\mathrm{Si}$ samples etched at different current densities. Insert shows the dependence of PL intensity vs $J$.

The effect of Si wafer resistivity on the porosity and pore depth was also determined using SOL-1 electrolyte solution. Si samples of different resistivity $(\rho=0.02,5.69,14.85$ and $17 \Omega \cdot \mathrm{cm})$ were selected for this part of the study. The SEM images of samples with higher resistivity $(14.85$ and $17 \Omega \cdot \mathrm{cm})$ are presented in Figs. 4. Although the plan view of the two samples (Figs. 4a,c) doesn't show much difference, however the cross-section views (Figs. 4b,d) show that the depth of the pores decreases with increasing of sample resistivity. This could be due to the decrease of the holes availability with increase of sample resistivity and hence, the decrease in the pore depth. The morphology of the samples also demonstrates a difference with the samples of low resistivity showing branched structures compared to the samples of slightly higher resistivity.

Fig. 5 shows the dependence of PL on the resistivity of $\mathrm{Si}$, and it can be seen that the PL intensity is higher for the samples with low resistivity. The plausible reason for this phenomenon is that the low resistivity Si samples form porous structures in nano-regime and as is well known the PL in porous Si arises from the quantum confinement in the nanocrystallite structures. Compared to this nano-regimed pores in $\mathrm{Si}$ with low resistivity, a highly ordered macro-porous $\mathrm{Si}$ is formed in samples with higher resistivity, and hence no PL seen in these samples.

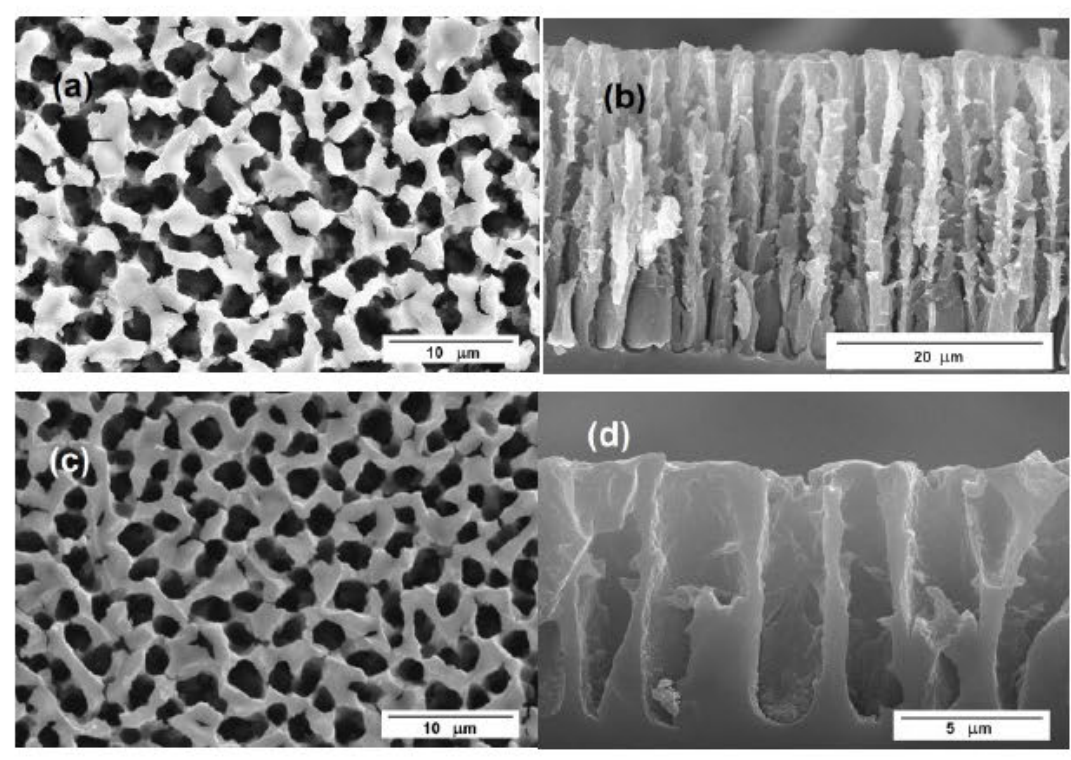

FIGURE 4. SEM images of sample etched in SOL-1 at anodisation time of $60 \mathrm{~min}$ and $J=10.03 \mathrm{~mA} / \mathrm{cm}^{2}$. (a) \& (b) $\rho=14.85 \Omega \cdot \mathrm{cm}$ and (c) \& (d) $\rho=17 \Omega \cdot \mathrm{cm}$.

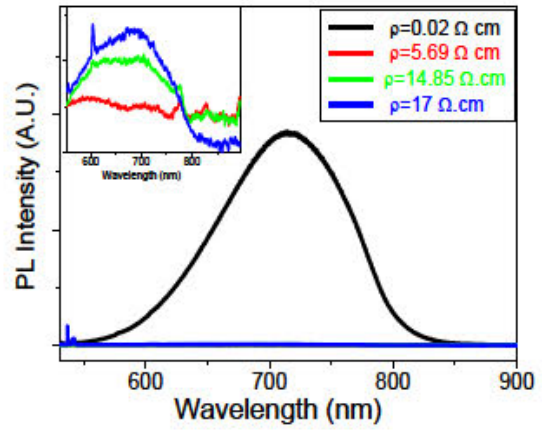

FIGURE 5. PL spectra of porous $\mathrm{Si}$ samples with different resistivities. Inset shows the PL spectra for higher resistivity 


\section{SUMMARY}

In conclusion, the paper describes the change in PL, pore-depth and porosity when silicon samples are subjected to etching using CTAC added ethanolic solutions of HF. The role of CTAC at a lower current density regime can be used to prepare good macro-porous $\mathrm{Si}$ samples. The dependence of photoluminescence versus current density revealed that PL intensity increases at higher current densities and for highly doped Si samples. The studies also revealed that an optimum etching current and time can be utilized for the preparation of good quality macro-porous silicon samples.

\section{ACKNOWLEDGMENT}

We thank E. Astrova for her useful suggestions and comments to this paper and L. Dumas for his help with the experiments.

\section{REFERENCES}

1. $\quad$ L.-S. Fan, Y.-C. Tai and R.S. Muller, IEEE Trans. Electron Devices, ED-35, 724-730 (1988).

2. $\quad$ R. L. Smith and S. D. Collins, J. Appl. Phys., 71, R1-R22 (1992).

3. H. Föll, M. Christophersen, J. Carstensen and G. Haase, Mater. Sci. Eng., R39, 93-141 (2002).

4. $\quad$ E. K. Propst and P.A. Kohl, J. Electrochem. Soc., 141, 1006-1013 (1994).

5. J.N. Chazalviel, F.Ozanam, N.Gabouze, S.Fellah and R.B.Wehrspohn, J. Electrochem. Soc. 149, C511-C520 (2002).

6. E.V. Astrova, T. N. Borovinskaya, A.V. Tkachenko, S. Balakrishnan, T. S. Perova, A. Rafferty and Y. K. Gun'ko, J. Micromech. Microeng., 14, 1022-1028 (2004).

7. V. Lehmann and S. Rönnebeck, J. Electrochem. Soc., 146, 2968-2975 (1999).

8. Y. Zhang, M. Yuan, B. Cai, D. Zhang, H. Chen and Y. Zhu, Optik, 127, 3009-3012 (2016).

9. L.T. Canham, Appl. Phys. Lett., 57, 1046-1048 (1990).

10. V. Lehmann and U. Gösele, Appl. Phys. Lett., 58, 856-858 (1991).

11. J.D. L. Shapley and D. A. Barrow, Thin Solid Films, 388, 134-137 (2001).

12. K.J. Chao, S.C. Kao, C.M. Yang, M.S. Hseu and T.G. Tsai, Electrochem. Solid-State Lett., 3, 489-492 (2000). 